\title{
Prevalence of Cognitive Impairment: Effects of Level of Education, Age, Sex and Associated Factors
}

\author{
José C. Millán-Calenti ${ }^{\mathrm{a}}$ Javier Tubío $^{\mathrm{a}}$ Salvador Píta-Fernández ${ }^{\mathrm{b}}$ Isabel González- \\ Abraldes $^{\mathrm{a}}$ Trinidad Lorenzo ${ }^{\mathrm{a}}$ Ana Maseda ${ }^{\mathrm{a}}$

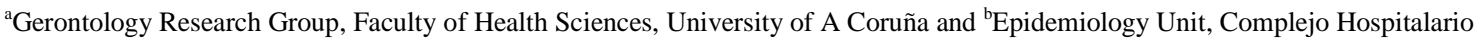 \\ Universitario, A Coruña, Spain
}

\section{Key Words}

Cognitive impairment . Level of education . Elderly . Associated factors

\begin{abstract}
Aims: To examine the prevalence of cognitive impairment in a Spanish elderly population and to analyse its association with some social and medical factors. Methods: We randomly selected a representative sample $(n=600)$ of people over 65 from Narón Council (A Coruña). Socio-demographic and biomedical data were collected and cognitive status was assessed using the Mini-Mental State Examination (MMSE). Results: We determined variations in the prevalence from $35.2 \%$, when age or level of education distribution was not applied, to $22.2 \%$ when they were applied. Women showed a higher probability of cognitive impairment than men. Negative correlation was observed between the age of the subject and the MMSE secore (Spearman correlation $\mathrm{p}=-0.45, \mathrm{p}<0.001$ ), with the possibility of developing cognitive impairment increasing each year. For our sample, cognitive impairment was associated with an increase of morbidity and mortality in the elderly population. This association was found with the presence of dementia. heart failure. anaemia, stroke and auditory deficits. Conclusions: Knowledge of the real prevalence rates, together with the establishment of adequate preventive and intervention measures, can be factors that may diminish the socio-sanitary impact of cognitive impairment.
\end{abstract}

\section{Introduction}

It is not clear if cognitive decline associated with old age is disease-related or whether it can occur as a part of so-called 'normal' ageing [1]. This 'normality' has been questioned, because subjects with cognitive deficits have been shown to be at increased risk for developing dementia compared to healthy control subjects [2, 3]. Moreover, several authors [4-8] have suggested an association between cognitive status and different pathologies like heart failure, stroke, diabetes, anaemia, hyperlipidaemia or sense organs alterations.

Based on the above findings, estimates of the prevalence of cognitive impairment in the elderly population are essential, both due to its social impact and its rate of conversion to dementia as well as its association with other pathologies, which increases exponentially as the illness advances [9].

There are various valid and reliable tools for clinical use and research for screening of people with cognitive impairment, such as the Short Portable Mental State Questionnaire [10]. the Mini-Cog [11] and the 7-min screening battery [12], among others, but the Mini-Mental State Examination (MMSE) developed by Folstein et al. [13], has become the most widely used and extensively studied method for assessing cognitive mental status [14].

On the other hand, many studies have proved that age, sex, and level of education have important effects on the total MMSE scores [14-16], so that appropriate corrections must be done when estimating the prevalence of cognitive impairment in the population.

The aim of this article was to determine the prevalence of cognitive impairment in a representative population of adults older than 65, reporting the effects of level of education, age and sex Secondly, we identified the pathologies associated with cognitive impairment because of their potential to increase mortality in this population. 


\section{Methods}

\section{Selection and Description o/ Participants}

The representative sample $(n=600)$ included people over 65 from Narón Council (A Coruña), randomly selected from the municipal register using a random number table and stratified by age quinquennia and sex (table 1, and ref. [17]). The level of confidence was $95 \%$, accuracy $\pm 4 \%$ and estimation for data losses $10 \%$. Nine subjects from the random sample were excluded due to data loss, as they were unable to be assessed with the MMSE be cause of their minimal level of consciousness,

Table 1. Distribution of the population by age group and gender, Naron 2000

\begin{tabular}{lll}
\hline Age group & \multicolumn{2}{l}{ Population } \\
\cline { 2 - 3 } & males $(\mathrm{n}=2,339)$ & females $(\mathrm{n}=3,118)$ \\
\hline & 916 & 957 \\
65-69 years & 653 & 779 \\
70-74 years & 415 & 586 \\
75-79 years & 209 & 400 \\
80-84 years & 146 & 396 \\
85 years and older & & \\
\hline
\end{tabular}

Source: population data [17]

\section{Procedure}

Participants were community subjects, living at their home. Participants were individually assessed in a Health Centre or at home in the case of people with mobility difficulties. The study protocol was submitted to the Ethics Committee at the University of A Coruña. Before data collection, all participants were informed about the study and signed the corresponding informed consent.

\section{Variables and lnstruments}

Age, sex and level of education were included among the socio-demographic data. Data related to general health status and bio- medical parameters were also collected based on the following criteria [18]: Total cholesterol greater than $250 \mathrm{mg} / \mathrm{dl}$ and triglycerides $200 \mathrm{mg} / \mathrm{dl}$ or above was considered hyperlipidaemia; anaemia was defined by haemoglobin value less than $13 \mathrm{~g} / \mathrm{dl}$ for men and less than 12 $\mathrm{g} / \mathrm{dl}$ for women.

With regard to the remaining pathologies suffered (personal background and illnesses), data were obtained from the subject anamneses, collecting the answers given by the patient him/herself or his/her relatives according to the medical records.

Cognitive impairment was modelled as a function of presence of hyperlipidaemia [high-density lipoprotein (HDL) and low-density lipoprotein (LDL) cholesterol], anaemia (haemoglobin level), haematocrit, creatinine, glycaemia, rheumatism. glaucoma, Parkinsonism, coronary disease, heart failure, diabetes, dementia, stroke, liver and kidney diseases, obesity, auditory and visual problems. This article only describes those with significant effects,

The MMSE [13] was used to assess cognitive status. This questionnaire includes items assessing 5 cognitive domains. A total possible score of 30 correspond to the highest cognitive status, with a cut-off score of 23 (lower or equal than 23) indicating cognitively impairment [13]. However, it has been proved that this cut-off score must be varied according to age and level of education, particularly when assessing an elderly population [19]. Crumer al. [14] have examined the distribution of age and educational level with the MMSE score. Therefore, these different thresholds were used to obtain the cut-off median score according to age and level of education. The acceptance rate to undergo the MMSE test was $98.5 \%$. Only 591 participants were able to undergo the MMSE.

A medical doctor (practitioner) and/or a trained nurse with extensive experience participated in the research for the clinical evaluation. This doctor was in charge of some of the patients during the research and also contacted other practitioners to follow the medical history of the rest of subjects to provide comprehensive ongoing knowledge of each patient's status. Those subjects without medical records from their respective practitioner were interviewed by the research doctor to establish their medical history. The overall personal functional status and service use of elderly were assessed with a questionnaire based on the standardized questionnaire from the Older Americans Resources and Services Multidimensional 
Functional Assessment Questionnaire. The MMSE was administered by a qualified clinical psychologist with extensive experience in cognitive assessment.

\section{Statistics}

Measurement comparisons were made by means of the Student's $t$ test and the Mann-Whitney U test. The Kolgomorov Smirnov test was performed previously to determine if the variables were normal or not, and so, a parametric or non-parametric test was used accordingly. The association of qualitative variables was estimated by means of the Xl statistic: the correlation among quantitative variables was estimated by the calculation of the Spearman $\mathrm{p}$. In order to determine which variables modified a dichotomic dependent variable, a multiple logistic regression analysis was performed, with other variables introduced in the model as predictors, from which the odds ratios (OR) along with their 95\% confidence intervals $(\mathrm{Cl})$ were calculated. The results for continuous variables are given as a mean with a standard deviation (SO). The level of significance was $\mathrm{p}<0.05$.

Statistical analyses were conducted using SPSS v. 16.0.1 [20].

\section{Results}

In (he sample, the mean age was 75.1 years $( \pm 7.5 \mathrm{SD})$, with a mean age of 75.9 years $( \pm 8.0 \mathrm{SD})$ for women and $73.9( \pm 6.7 \mathrm{SD})$ for men.

Differences were found in the prevalence of cognitive impairment, depending on the assessment criterion used to screen for cognitive impairment (table 2). In this sample, $35.2 \%$ (45.2\% of women and $22 \%$ of men) presented cognitive impairment according to the MMSE (cut-off at 23), when no distribution by age or level of education were made. These figures were substantially modified when applying the aforementioned distribution: $22.2 \%$ of the sample presented cognitive impairment, with significant differences ( $\mathrm{p}<0.001$ ) by sex, $28.6 \%$ of women presented cognitive impairment versus $13.7 \%$ of men, being more likely to have cognitive impairment (OR $=2.19 ; 95 \% \mathrm{CI}$ : 1.39-3.35). In general, women obtained a significantly lower mean MMSE score ( $p$ < 0.001$)$ than men $(22.6 \pm 6.2$ vs. $25.5 \pm 4.2)$ within all age levels (table 3 ).

Table 2. Prevalence rates for cognitive impairment by sex. MMSE cut-off scores by age and level of education [14] and cut-off at 23

\begin{tabular}{lll}
\hline & $\mathrm{n}$ & Prevalence $(95 \% \mathrm{CI})$ \\
\hline $\begin{array}{l}\text { MMSE (cut-off scores by age and educational level) } \\
\text { Sex }\end{array}$ & \\
$\quad$ Men & $35 / 255$ & $13.7(0.3-3.7)$ \\
$\quad$ Women & $96 / 336$ & $28.6(23.7-33.8)$ \\
Total & $131 / 591$ & $22.2(18.9-25.8)$ \\
& & \\
\hline MMSE (cut-offat 23) & & \\
Sex & & $22.0(17.1-26.6)$ \\
$\quad$ Men & $56 / 255$ & $45.2(39.9-50.7)$ \\
$\quad$ Women & $152 / 336$ & $35.2(31.4-39.2)$ \\
Total & $208 / 591$ & \\
& & \\
\hline
\end{tabular}

We observed a negative correlation between age of subjects and MMSE (Spearman correlation $\mathrm{p}=$ $0.45, \mathrm{P}<0.001)$ score. Table 4 shows the distribution of the prevalence of cognitive impairment by age quinquennia, sex and level of education, establishing 23 as a cut-off or MMSE scores by age and level of education. Subjects presenting more cognitive impairment were those of higher age, i.e. older than 85 years of age. The probability of developing cognitive impairment increases on a yearly basis $(\mathrm{OR}=1.11$; 95\% CI: 1.08-1.14), with the mean age of people with cognitive impairment higher than that of people without it (80.1 years vs. 73.6 years). Moreover, mean MMSE scores obtained for each age quinquennium indicate that, for both men and women, cognitive functioning significantly decreased $(\mathrm{p}<$ 0.001 ) with age (table 3$)$. 
Table 3. MMSE scores by age and sex (mean \pm SD)

\begin{tabular}{llll}
\hline Age, years & Men & Women & Total \\
\hline & & & \\
$65-69$ & $26.4 \pm 3.9$ & $25.6 \pm 3.4$ & $26.1 \pm 3.7$ \\
$70-74$ & $26.8 \pm 2.6$ & $24.4 \pm 5.8$ & $25.5 \pm 4.7$ \\
$75-79$ & $24.8 \pm 3.5$ & $23.2 \pm 5.1$ & $23.9 \pm 4.5$ \\
$80-84$ & $24.3 \pm 4.8$ & $19.9 \pm 5.6$ & $21.5 \pm 5.7$ \\
$\geq 85$ & $22.6 \pm 6.9$ & $17.8 \pm 5.5$ & $19.3 \pm 6.7$ \\
\hline \multirow{2}{*}{ Total } & $25.5 \pm 4.2$ & $22.6 \pm 6.2$ & $23.9 \pm 5.6$ \\
& & & \\
\hline
\end{tabular}

Level of education was also significantly correlated $(p<0.001)$ with cognitive impairment. Most of the subjects with cognitive impairment had less than 4 years of schooling.

After carrying out a multivariate analysis associating cognitive impairment with the pathologies suffered by the sample subjects, we found an association between cognitive impairment and heart failure $(\mathrm{p}=0.017)$, anaemia $(\mathrm{p}=0.043)$, stroke $(\mathrm{p}=0.016)$; dementia $(\mathrm{p}<0.001)$ and auditory deficits $(\mathrm{p}=$ 0.007). However, we did not find an association between cognitive impairment and hyperlipidemia, diabetes or eyesight problems.

\section{Discussion}

The results indicate that the prevalence of cognitive impairment varies considerably depending on the criterion used to screen for cognitive impairment [21], producing much higher figures when the appropriate corrections based on age and level of education are not made.

It has been proven that sex has an important effect on the cognitive impairment, though it has not been considered in many studies [15. 16.22].

Our results show that, for the same age level, there is a greater prevalence of cognitive impairment among women than among men. These data are in concordance with other authors' data [23-25], who suggest that this difference is more pronounced amongst people aged $>80$ years.

Compared to these findings, significant differences (15) between both sexes were only found when comparing groups of men and women with low levels of education (less than 4 years of schooling). Amongst this group of individuals with a low level of education, men obtained better scores than women. In some cases, results are contradictory, as in the case of a Canadian sample, in which women obtained higher MMSE scores than men [22].

Despite the results, we understand there is evidence of more cognitive impairment in women. More studies should be carried out to determine which factors are producing this clear result, which is unlikely solely due to higher mortality amongst men.

In our study, the estimation of the prevalence for any type of cognitive impairment in an elderly sample was slightly higher than in other studies $[23,26]$, in which approximately an $18 \%$ prevalence of cognitive impairment was found. Nevertheless, these differences may be related to the cut-off used in the MMSE when categorising the presence of cognitive impairment and the age level of the studied population. Consequently, the use of different categorisation criteria can produce some differences in prevalence across different studies, In our study, as we have already stated above, we have considered it more appropriate to determine the cut-off in the MMSE for each subject based on his/her age and level of education [14]. However, we also show the obtained figures without applying these criteria, finding differences for both sexes in all age groups. Thus, it is dearly shown how the prevalence of cognitive impairment increases when no distribution by age and level of education are applied.

Different studies with elder1y European samples [3,27] showed rates of prevalence between 21 and $27 \%$, which are in concordance with those obtained in our study, once the influence of age and level of education are corrected. On the other hand, our results match those obtained in the Aging, Demographics and Memory Study (ADAMS), which was 22.2\% 128J. In addition, the prevalence of cognitive impairment appears to be higher in developed countries than in underdeveloped areas, as observed with a prevalence of cognitive impairment of $10.4 \%$ in an elderly African sample [29]. 
Table 4. Prevalence rates for cognitive impairment by age, sex and level of education, with [14] and without distribution of MMSE scores by age and educational level

\begin{tabular}{|c|c|c|c|c|}
\hline & \multicolumn{2}{|l|}{ Men } & \multicolumn{2}{|l|}{ Women } \\
\hline & $\mathrm{n}$ & prevalence $(95 \% \mathrm{CI})$ & $\mathrm{n}$ & prevalence $(95 \% \mathrm{CI})$ \\
\hline \multicolumn{5}{|c|}{ MMSE (cut-off scores by age and educational level) } \\
\hline \multicolumn{5}{|l|}{ Age, years } \\
\hline $65-69$ & 9/S5 & $10.6(5,3-19.6)$ & $11 / 87$ & $12,6(6,8-21.9)$ \\
\hline $70-74$ & $7 / 72$ & $9.7(4.32-19.8)$ & $12 / 82$ & $14.6(8.1-24.6)$ \\
\hline $75-79$ & $9 / 50$ & $18.0(9.0-31.9)$ & $22 / 67$ & $32.8(22.2-41.5)$ \\
\hline $80-84$ & $3 / 27$ & $11 . \backslash(2.9-30.3)$ & $18 / 48$ & $37.5(24.3-56.7)$ \\
\hline$\geq 85$ & $7 / 21$ & $33.3(14.5-56.9)$ & $33 / 52$ & $63.5(48.9-76.0)$ \\
\hline \multicolumn{5}{|l|}{ Education, years } \\
\hline $0-4$ & $26 / 195$ & $13.3(9.1-19.1)$ & $86 / 304$ & $28.3(23.4-33.8)$ \\
\hline $5-8$ & $7 / 46$ & $15.2(6.8-29.5)$ & $2 / 23$ & $8.7(1.5-29.5)$ \\
\hline $9-12$ & $1 / 11$ & $9.1(0.5-42.9)$ & $0 / 3$ & $0.0(0.0-69.0)$ \\
\hline College or higher degree & $1 / 3$ & $33.3(1.76-87.5)$ & $2 / 2$ & $100.0(19.8-100.0)$ \\
\hline \multicolumn{5}{|l|}{ MMSE (cut-off at s 23) } \\
\hline \multicolumn{5}{|l|}{ Age, ycars } \\
\hline $65-69$ & $11 / 85$ & $12.9(6.9-22.4)$ & $20 / 87$ & $23.0(14.9-33.5)$ \\
\hline $70-74$ & $9 / 72$ & $12.5(6.2-22.9)$ & $24 / 82$ & 29.3 (2D.O-40.5) \\
\hline $75-79$ & $17 / 50$ & $34.0(21.6-48.9)$ & $31 / 67$ & $46.3(34.2-58.8)$ \\
\hline $80-84$ & $9 / 27$ & $33.3(17.2-54.0)$ & $32 / 48$ & $66.7(51.5-79.1)$ \\
\hline$\geq 85$ & $10 / 21$ & $47.6(26.4-69.7)$ & $45 / 52$ & $86.5(/ 3.6-94.0)$ \\
\hline \multicolumn{5}{|l|}{ Education, years } \\
\hline $0-4$ & $53 / 195$ & $27.2(21.2 .-34.1)$ & $143 / 304$ & $47.0(41.3-52.8)$ \\
\hline $5-8$ & $3 / 46$ & $6.5(1.7-18.9)$ & $1 / 23$ & $4.3(0.21-24.0)$ \\
\hline $9-12$ & $\mathrm{o} / \mathrm{u}$ & $0.0(0.0-32.1)$ & $0 / 3$ & $0.0(0.0-69.0)$ \\
\hline College or higher degree & $0 / 3$ & $0.0(0.06-9.0)$ & $0 / 2$ & $0.0(0.0-80.2)$ \\
\hline
\end{tabular}

The risk of cognitive decline increases [30, 31] during the process of aging. In our study, we found the most significant increases in the prevalence of cognitive impairment (both for men and women) in the age range of 75-79, increasing again after 85 years of age.

The greatest prevalence of cognitive impairment in the elderly has been found amongst those with the lowest levels of education [32], as was shown in our study, which reflects the situation in Spain (few people aged $>65$ years have more than 9 years of schooling). We did not have a homogeneous distribution with regard to the level of education, implying that the obtained percentages of prevalence for the highest level of educations are due to bias and do not represent the reality of OUT study sample. AI-though frequently used and practical, the MMSE is a relatively crude measure of cognitive impairment. It has a ceiling effect, which limits the detection of dementia in well-educated populations [33].

On the other hand, there is evidence associating cognitive decline with certain pathologies, mainly heart disease, diabetes, stroke, anaemia, hyperlipidaemia, and sensory deficits [4-8]. Furthermore, longitudinal studies suggest that subjects with objectively demonstrated cognitive deficits, albeit without dementia, have been shown to be at increased risk of dementia, with rates of conversion estimated to be between $10 \%$ and $15 \%$ each year [2]. These figures go up to $18 \%$ over 3 -year monitoring [3]. Due to this, cognitive impairment has been associated with a higher risk of mortality [34].

Our results replicate other findings, which suggest a relationship between cognitive impairment and certain pathologies. In particular, we found that heart failure, stroke, anaemia, dementia and auditory deficits are significantly associated to cognitive impairment, In contrast, we could not establish any association between cognitive detriment and diabetes or hyperlipidemia, replicating result from at least 2 other studies, which also did not find either evidence of higher cognitive decline in a sample of diabetic elders [35J or an association between hyperlipidemia at baseline with change in cognitive test scores [7].

In conclusion, there is a high prevalence of cognitive impairment among people aged $>65$ years, and it is more evident in women than men with increasing age. These rates should be corrected based on age and level of education criteria; otherwise, the estimated prevalence is too high. On the other hand, cognitive impairment is significantly associated with dementia and other health problems, such as heart failure, stroke, anaemia and auditory problems. 
Regular assessment of cognitive function should be performed on the elderly due to its important value as a predictor of morbidity and mortality.

\section{Acknowledgements}

We sincerely thank the Narón Council for providing us access to their elderly population.

\section{References}

1 Starr JM, Deary IJ, .lnch S, Cross , MacLennan WI: Age-associated cognitive decline in healthy old people, Age Ageing 1997;26:295-300.

2 Petersen RC, Smith GE, Waring SC: Mild cognitive impairment: clinical characterization and outcome, Arch Neurol 1999;56: 303-308.

3 Ritchie K, Artero S, Touchon J: Classification criteria for mild cognitive impairment: a population-based validation study. Neurology 2001;56:37-42.

4 Lindenberger U, Bailes PB: Sensory functioning and intelligence in old age: a strong connection. Psychol Aging 1994;9:339-355.

5 Kalmijn S, Feskens EJ, Launer LJ, Stijnen T, Kromhoul D: Glucose intolerance, hyperinsulinaenemia and cognitive function in a general population of elderly men. Diabetología 1995;38: 1096-1102.

6 Cacciatore F, Abete P, Ferrara N, Calabrese e, Napoli C, Maggi S. Varricchio M, Rengo F: Congestive heart failure and cognitive impairment in an older population. Osservatorio Geriatrico Campano Study Group. J Am Geriatr Soc 1998:46: 1343-1348.

7 Knopman D, Boland LL, Mosley T, Howard G, Liao D, Szklo M, McGovern P, Folsom AR: Cardiovascular risk factor and cognitive decline in middle-aged adults. Neurology 2001; 56:42-48.

8 Steen RG, Miles MA, Helton KJ, Strawn S, Wang W, Xiong X, Mulhern RK: Cognitive impairment children with hemoglobin SS sickle cell disease: relationship lo MR imaging findings and hematocrit. AJRN Am J Neuroradiol 2003;24:382-389.

9 Roca-Santiago HM, Lago-Bouza IR, Millán-Calcnrí JC, Gómez-Ulla-Irazazábal F: Alzheimer's disease and age-related macular degeneration (in Spanish). Arch Soc Esp Oftalmo 2006;81:73-78.

10 Pfeiffer E: A short Portable Mental Status Questionnaire for the assessment of organic brain deficit in the elderly patients. J Am Geriatr Soc 1975;23:433-441.

11 Borson S, Seanlan J, Rrush M, Vitaliano P, Dokmak A: The Mini-Cog: a cognitive 'vital signs' measure for dementia screening in multi-lingual elderly. Int J Geriatr Psychiatry. 2000;15:1021-1027.

12 Solomon PR, Hirschoff A, Kelly B, Relin M, Brush M, DeVeaux RD, Pendlebury WW: A 7 minute neurocognitive screening battery highly sensitive lo Alzheimer's disease. Arch Neurol 1998;55:349-355.

13 Folstein MF, Folstein DE, McHugh PR: 'Mini-Mental State'; a practical method for grading the cognitive state of patients for the clinician. J Psychiatry Res 1975;12:189-198.

14 Crum RM, Anthony IC, Bassett SS, Folstein MF: Population-based norms for the Mini Mental State Examination by age and level of education. JAMA 1993;269:2386-2391.

15 Rosselli D, Ardila A, Pradilla C, Morillo L, Bautista L, Rey O, Carnacho M: The Mini-Mental State Examination as a selected diagnostic selection test for dementia: a Colombian population study. GENECO (in Spanish), Rev Neurol 2000;30:428-432.

16 Jones RN, Gallo JJ: Education and sex differences in the Mini Mental State Examination. Effects of differential item functioning. J Gerontol B Psicol Sci Soc Sci 2002;57:548-558.

17 INE (Instituto Nacional de Estadística). Population Demographic Censuses (in Spanish). Municipal Register 2000. 2000.

18 Fauci AS, Braunwald E, Kasper DL, Hauser SI, Longo DJ, Jameson JL, Loscalzo J: Harrison's Principies of Internal Medicine. ed 17. London, McGraw-Hill. 2008.

19 Weiss BD, Reed R, Kligman KW, Abyad A: Literacy and performance on the Mini-Mental State Exanimation. J Am Geriatr Soc 1995:431807-810.

20 SPSS Inc.: SPSS Base 16.0.1 for Windows User's Gulde. Chicago, SPSS. 2007.

21 Kumar R, Dear KB, Christensen H, Ilschner S, Jorm AF, Meslin C, Rosenman SI, Sachdev PS: Prevalence of mild cognitive impairment in 60- to 64 year-old community-dwelling individuals: The Personality and Total Health through Life 60+ Study. Dement Geriatr Cogn Disord 2005; 19:67-74.

22 Tombaugh TN, McDowell I, Kristjansson B, Hubley AM: Mini Mental State Examination (MMSE) and the modified MMSE (3M): a psychometric comparison and normative data. Psychol Assess 1996;8:48-59.

23 Rait C, Fletcher A, Smeeth L, Brayne C, Stirling S, Nunes M, Breeze E, Siu-Woon E, Bulpitt CJ, Jones D, Tulloch AJ: Prevalence of cognitive impairment: results from the MRC trial of assessment and management of older people in the community. Age Ageing 2005; 34:242-248.

24 Heeren TJ, Lagaay AM, Hijmans W: Prevalence of dementia in the oldest old of a Dutch community. J Am Geriatr Soc 1995;39:755-759.

25 Zhang Z: Gender differentials in cognitive impairment and decline of the oldest old in China. I Gerontol B Psychol Sci Soc Sci 2006: 61 B; SI07-S1I5.

26 Braync C, Nickson C, McCracken C: Cognitive function and dementia in six areas of England and Wales: the distribution of MMSE and the prevalence of GMS organicity level in the MRC CFA study. Psychol Med 1998:28:319-335.

27 Graciani A, Banegas JR, Guallar-Castillon P, Domínguez-Rojas V, Rodríguez-Artalejo F: Cognitive assessment of nondemented elderly community dwellers in Spain. Dement Geriatr Cogn Disord 2006;21: 104-112.

28 Plassman BL, Langa KN, Fischer GG, Heeringa SG, Weir DR, Ofstedal MB, Burke JR, Hurd MD, Potter GG, Rodgers WL, Steffens DC, McArdle JJ, Willis RJ, Wallace RB: Prevalence of cognitive impairment without dementia in the United States. Ann Intern Med 2008; 148:427-434. 
29 Guerchet M, Houinato D, Paraiso MN, von Ahsen N, Nubukpo P, Otto M, Clément JP, Preux PM, Dartigues JF: Cognitive impairment and dementia in elderly people living in rural Benin, West Africa. Dement Geriatr Cogn Disord 2009;27:34-41.

30 Morta M, Ferlito L, Magnolfi SU, Petruzzi E, Pinzani P, Malentacchi F, Petruzzi I, Bennari E, Malaguarnera M: Cognitlve and functional status in the extreme longevity. Arch Geronlol Ger 2008;46:245-252.

31 Suthers K, Kirn JK, Crimmins E: Life expectancy with cognitive impairment in the older population of the United States. J Gerontol B Psychol Sci Soc Scí 2003;58B:S179-S186.

32 Rosselli M, Tappen R, Williams C, Salvatierra J: The relation of education and gender on the attention items of the Mini-Mental State Examination in Spanish speaking Hispanic elders. Arch Clin Neuropsychol 2006; 21:677-686.

33 Reisberg B, Burns A, Brodaty H, Eastwood R, Rossor M, Sartorius N, Winblad B; Diagnosis of Alzheimer's disease: report of an international Psychogeriatric Association Meeting Work Group. Int Psychoger 1997:9(supp 1):11-38.

34 Freedberg DE, Dave J, Kurth T, Gaziano MJ, Bludau JHA: Cognitive impairment over the age of 85: hospitalization and mortality. Arch Gerontol Geriatr 2008;45:137-145.

35 Seotl RD, Krirz-Silverstem D, Barren-Connor E, Wiederhoh WC: The association of non-insulin dependent diabetes mellitus and cognitive function in an older cohort. J Am Geriatr Soc 1998;46: 1217-1222. 